\title{
МОНИТОРИНГ ТЕРРИТОРИЙ С ИСПОЛЬЗОВАНИЕМ СПЕКТРАЛЬНЫХ ИНДЕКСОВ
}

\section{Владислав Александрович Косолапов}

Сибирский государственный университет геосистем и технологий, 630108, Россия, г. Новосибирск, ул. Плахотного, 10, обучающийся, тел. (999)464-09-62, e-mail: Kosolapov-VA2016@sgugit.ru

\section{Елена Павловна Хлебникова}

Сибирский государственный университет геосистем и технологий, 630108, Россия, г. Новосибирск, ул. Плахотного, 10, доцент кафедры фотограмметрии и дистанционного зондирования, тел. (913)901-94-58, e-mail: e.p.hlebnikova@sgugit.ru

В статье рассматриваются преимущества обработки данных дистанционного зондирования при мониторинге территорий с использованием спектральных индексов, а также описываются методы улучшения результатов при использовании урбанизированных спектральных индексов.

Ключевые слова: спектральные индексы, мониторинг, вегетационный индекс, урбанизированный индекс, дистанционное зондирование, индексное изображение, космические снимки

\section{TERRITORY MONITORING USING SPECTRAL INDICES}

\section{Vladislav A. Kosolapov}

Siberian State University of Geosystems and Technologies, 10, Plakhotnogo St., Novosibirsk, 630108, Student, Department of Photogrammetry and Remote Sensing, phone: (999)464-09-62, e-mail: Kosolapov-VA2016@sgugit.ru

\section{Elena P. Khlebnikova}

Siberian State University of Geosystems and Technologies, 10, Plakhotnogo St., Novosibirsk, 630108, Russia, Associate Professor, Department of Photogrammetry and Remote Sensing, phone: (913)901-94-58, e-mail: e.p.hlebnikova@sgugit.ru

The article discusses the advantages of processing remote sensing data when monitoring territories using spectral indices, and also describes methods for improving the results when using urbanized spectral indices.

Keywords: spectral indices, monitoring, vegetation index, urbanized index, remote sensing, index image, satellite images

\section{Введение}

Одним из ключевых преимуществ дистанционного зондирования является возможность исследования обширных территорий. При сборе необходимой информации об интересующем земельном участке, природном или промышленном объекте используется аэрокосмическая съемка. Данный вид съемки позволяет не 
только осуществлять сбор большого количества данных, но и производить мониторинг, который является фундаментом для создания различных прогнозов.

Перспективы развития технологий дистанционного зондирования привлекают большое число исследователей, что увеличивает количество сфер деятельности, использующих дистанционные методы для решения собственных задач [3-5]. На данный момент дистанционное зондирование используется в геологии, картографии, гляциологии, строительстве, природоохранных сферах, нефтедобывающей промышленности, мониторинге антропогенных объектов и т. д.

Использование технологий дистанционного зондирования открывает обширные возможности отслеживания изменений свойств пространственных объектов. Снимки с космических съемочных аппаратов позволяют производить ежедневный мониторинг. При использовании съемочных систем для дистанционных зондирования земли создается обширный поток данных, имеющий вид мультиспектральных снимков. В зависимости от решаемой задачи мультиспектральные снимки подвергаются разного рода преобразованиям. Помимо базовых преобразований яркости и контрастности присутствуют и преобразования, в корне меняющие яркостные значения спектральных каналов (Principal Component, Tasseled сар), при этом улучшая различимость объектов, что положительно сказывается на их дешифрировании.

Одним из распространенных видов преобразований снимков являются индексные изображения, позволяющие определять значения яркости каждого пикселя путем применения арифметических операций над значениями яркости этого пикселя из разных каналов снимка. Таким образом, практически каждый исследуемый объект имеет несколько вариаций подходящих спектральных индексов, которые, в свою очередь, подбираются эмпирически, учитывая особенности территории, объекта или факторов, влияющих на съемку [1, 2, 6-15]. Спектральные индексы позволяют автоматически выделять объекты исследования, а также производить мониторинг не только изменений физических характеристик объектов, но и внутренних процессов.

\section{Методы и материалы}

Наибольшее распространение спектральные индексы получили в сельскм хозяйстве, благодаря вегетационному индексу NDVI фермеры имеют возможность ежедневно оценивать всхожесть растений. Составлять оценку всхожести растительных культур становится возможным за счет того, что NDVI являться простым количественным показателем активной биомассы. При расчете спектрального индекса NDVI используются видимый красный и ближний инфракрасный диапазон электромагнитного излучения, формула (1):

$$
N D V I=\frac{N I R-R E D}{N I R+R E D},
$$

где RED - видимый красный канал;

NIR - ближний инфракрасный канал. 
Данная комбинация спектральных диапазонов позволяет рассчитать NDVI для любой космической съемочной системы. Диапазоны значений для каждого этапа всхожести растений показаны на рис. 1.

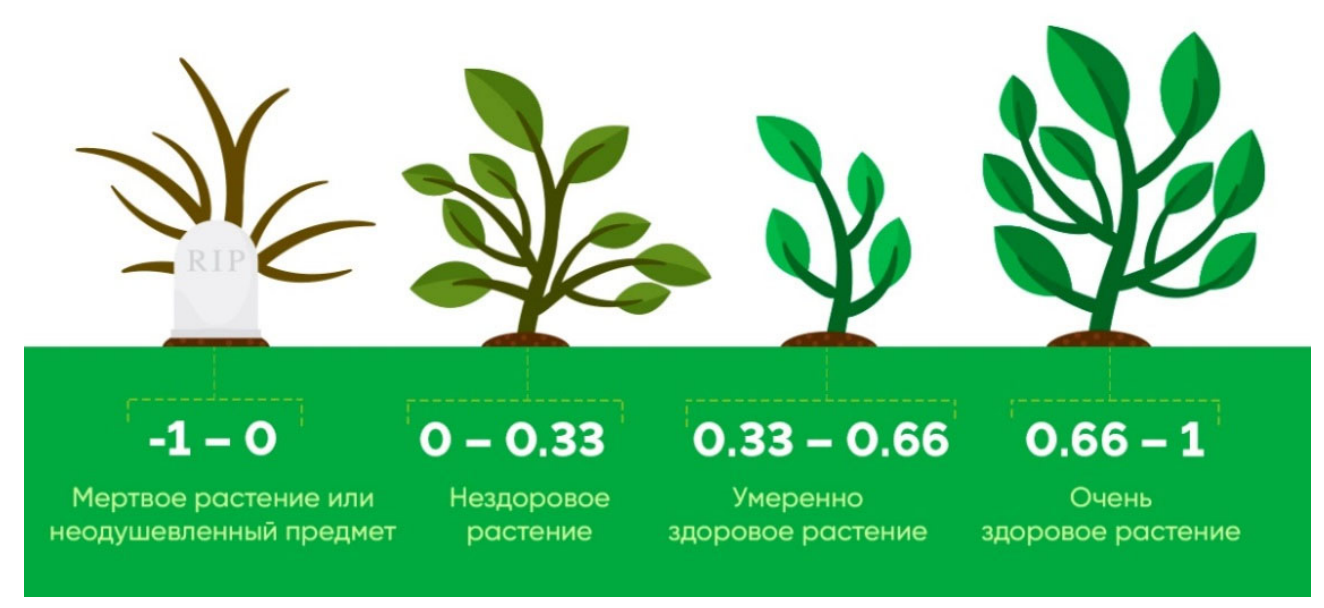

Рис. 1. Этапы всхожести растений

Несмотря на практичность использования индекса NDVI, существую другие разновидности вегетационных индексов, например: ARVI, SAVI, RVI и т.д.

\section{Результаты}

Решение задач по мониторингу площадей с растительным покровом в большинстве случаев не является затруднительным. Абсолютно иначе обстоит ситуация с мониторингом антропогенных объектов. Сложность распознавания объектов, созданных в процессе жизнедеятельности человека, заключается в их неоднородности. Города, поселки, промышленные зоны являются пространственными объектами, имеющими большое количество разнородных отражательных свойств, из-за чего использование спектральных индексов не всегда дает требуемый результат.

Одними из используемых спектральных индексов для мониторинга антропогенных объектов являются UI и BU, формулы $(2,3)$ :

$$
U I=\left(\frac{S W I R 2-N I R}{S W I R 2+N I R}+1\right) * 100,
$$

где SWIR - коротковолновый инфракрасный диапазон;

NIR - ближний инфракрасный канал.

$$
B U=N D B I-N D V I,
$$

где NDBI - стандартизованный индекс различий застройки; 
NDVI - нормализованный разностный индекс растительности.

Результаты использования спектральных индексов UI и BU на близлежащей территории города Екатеринбург, показаны на рис. 2 и 3.

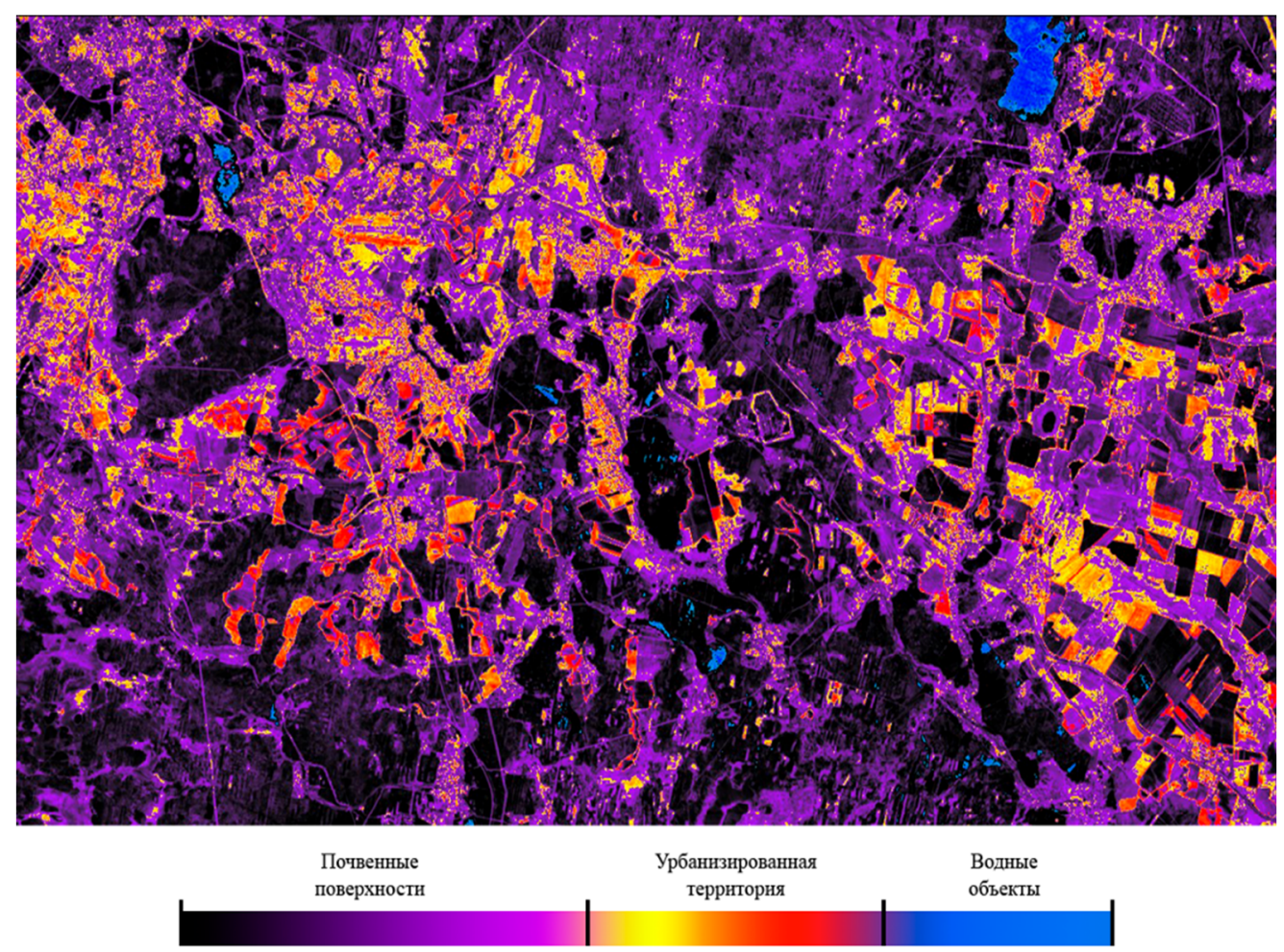

Рис. 2. Использование спектрального индекса UI на близлежащую территорию г. Екатеринбург, на основе снимков Sentinel-2

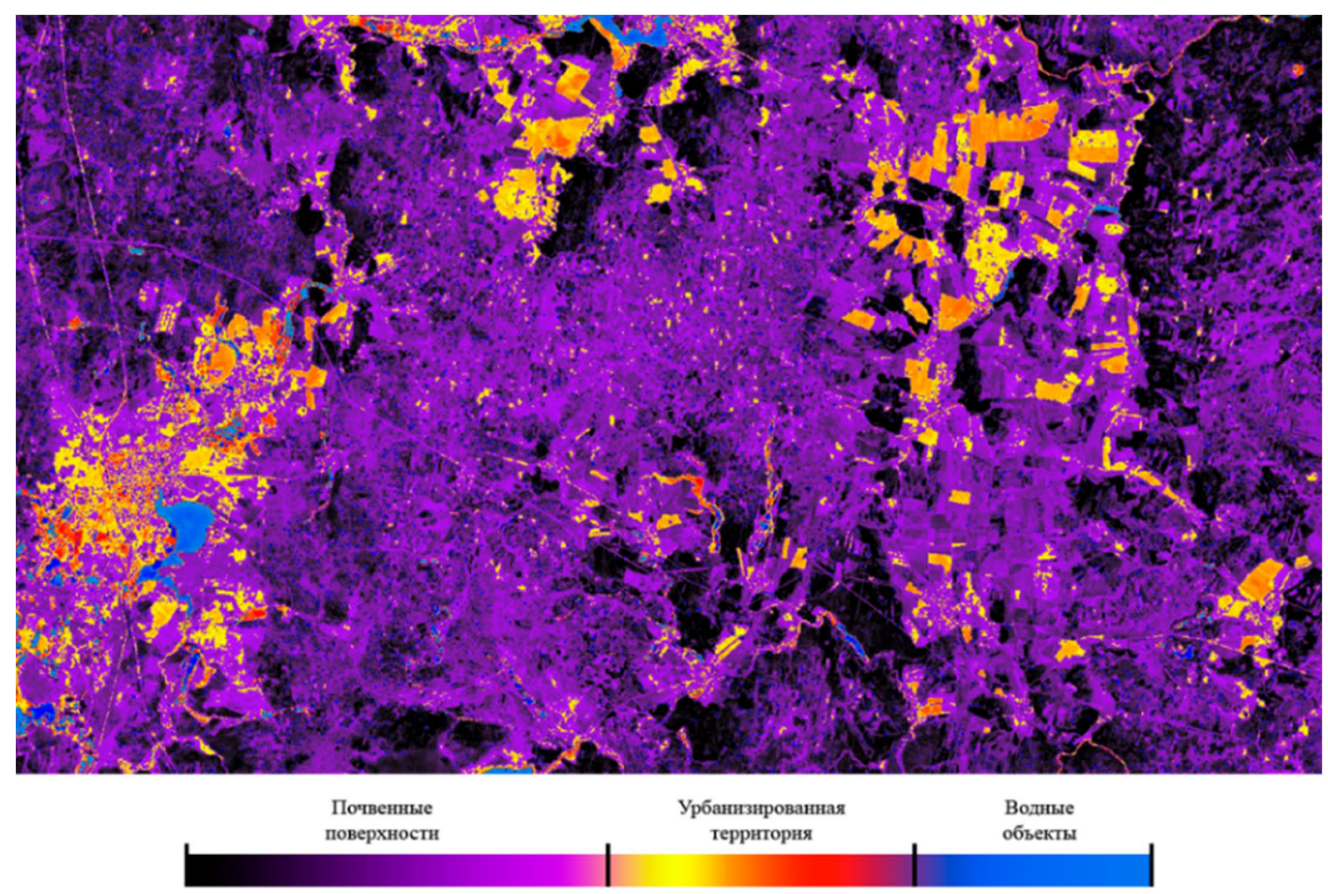


Рис. 3. Использование спектрального индекса BU на близлежащую территорию г. Екатеринбург, на основе снимков Sentinel-2

Из-за большого количества разнородных объектов внутри антропогенных зон, яркостные значения интересуемой зоны смешиваются с окружающей средой, не предоставляя полезную информацию. Проанализировав данный пример можно выделить проблемные участки в виде пересечения яркостных значений почвенных поверхностей и урбанизированных территорий. Для решения данной задачи были произведены дополнительные вычисления, в следствие чего был создан новый спектральный индекс для выделения урбанизированных территорий SBUI, формула (4):

$$
S B U I=B U-S A V I,
$$

где $\mathrm{BU}$ - индекс застроенных территорий;

SAVI - почвенный вегетационный индекс.

Результаты использования SBUI показаны на рис. 4.
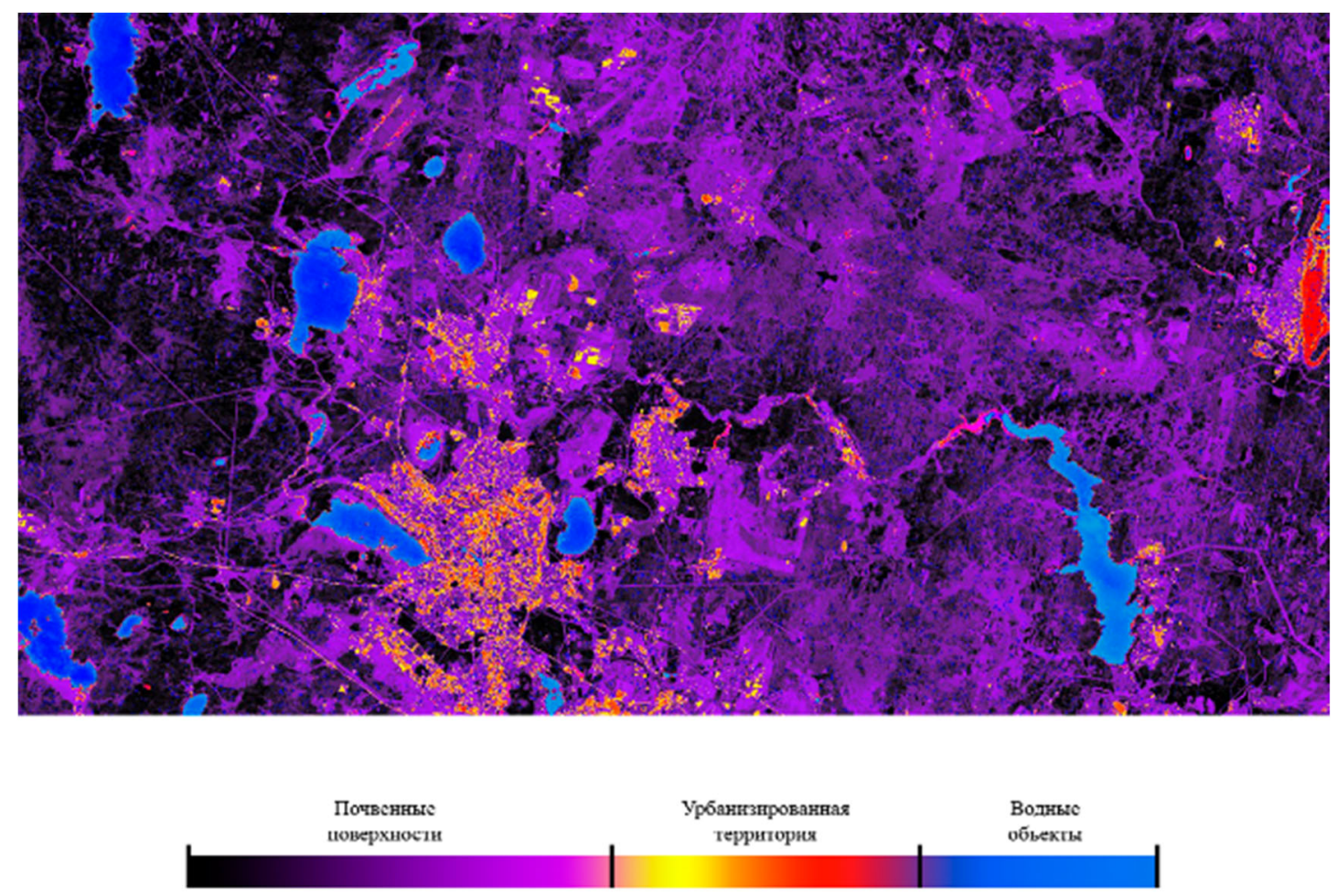

Рис. 4. Использование спектрального индекса SBUI на близлежащую территорию Екатеринбурга, на основе снимков Sentinel-2

\section{Обсуждение}

Спектральный индекс SBUI позволяет приглушать яркостные значения растительного и почвенного покрова, из-за чего происходит разделение со значениями антропогенных территорий. SBUI также отчетливо отделяет яркостные 
значения водных поверхностей, что также служит преимуществом данного спектрального индекса.

Используя спектральные индексы для выделения антропогенных зон нужно тщательно проанализировать близлежащую территорию для подбора оптимального набора вспомогательных спектральных индексов. После чего следует произвести дополнительные вычисления для устранения наиболее проблемных участков в местах пересечения яркостных значений различных пространственных объектов.

\section{Заключение}

Для выявления ценной информации космические снимки должны пройти процесс тематической обработки, включающей в себя дешифрирование пространственных объектов. На данный момент самыми распространенными являются автоматизированные методы дешифрирования. В эти методы входят как разновидности классификаций, так и индексные изображения. Индексные изображения являются достаточно функциональным инструментарием при тематической обработке, они позволяют автоматизировать дешифрирование и увеличить его оперативность.

Проведенные эксперименты и анализ результатов позволили разработать собственную модификацию индекса застроенных территорий.

Полученные в результате расчетов индексов изображения обладают большой информативностью и могут использоваться как составляющие синтезированных изображений для автоматической или управляемой классификации, что увеличивает спектр применения индексных изображений.

\section{БИБЛИОГРАФИЧЕСКИЙ СПИСОК}

1. Вегетационные индексы [Электронный ресурс] / глав. страница. - Электрон. дан. -М., 2020. - Режим доступа: https://gis-lab.info/qa/vi.html.

2. Галерея индексов [Электронный ресурс] / отдел «Обработка и анализ». - Электрон. дан. - М., 2015. - Режим доступа: https://pro.arcgis.com/ru/pro-app/help/data/imagery/indicesgallery.htm.

3. Дворкин, Б. А. Новейшие и перспективные спутники дистанционного зондирования Земли / Б. А. Дворкин, С. А. Дудкин // Геоматика. - 2013. - № 2. - С. 16-21.

4. Евдокимов, С. И. Определение физического смысла комбинации каналов снимков Landsat для мониторинга состояния наземных и водных экосистем [Текст] / С. И. Евдокимов, С. Г. Михалап // Серия «Естественные и физико-математические науки». -2015. № 7. - С. 21-32.

5. Журкин, И. Г Геоинформационное моделирование и картографирование природноресурсного потенциала интенсивно развивающихся территорий [Текст] / И. Г. Журкин, В. С. Грузинов, Л. Н. Чабан // Издательство МИИГАиК. -2012. -53 с.

6. Курганович, К. А. Использование водных индексов для оценки изменения площадей водного зеркала степных содовых озер юго-востока Забайкалья, по данным дистанционного зондирования [Текст] / К. А. Курганович, Е. В. Носкова // Вестник ЗабГУ. -2015. - № 06. C. $16-24$. 
7. Морозова, В. А. Расчет индексов для выявления и анализа характеристик водных объектов с помощью данных дистанционного зондирования [Электронный ресурс] / В. А. Морозова // Современные проблемы территориального развития. -2019. - № 2. - С. 1-12.

8. Применение вегетационных индексов для картографирования ландшафтов Большого Кавказа [Текст] : оригинальная статья / В. В. Братков [и др] ; под ред. Н. М. Савицкого, Л. Н. Плехановой. - 4-е изд. стер. - М. : Известия ДГПУ, 2016. - С. 97-111.

9. Пушкин, А. А. Оценка возможностей использования спектрального вегетационного индекса EVI для дешифрирования лесных насаждений по материалам космической съемки [Текст] / А. А. Пушкин, Н. Я. Сидельник, С. В. Ковалевский// Труды БГТУ. - 2020. - № 1. C. 5-11.

10. Черепанов, А. С. Спектральные свойства растительности и вегетационные индексы [Текст] / А. С. Черепанов, Е. Г. Дружинина // Геоматика. -2009. - № 3. - С. 28-32.

11. David, P. R. Remote Sensing of Fire Severity: Assessing the Performance of the Normalized Burn Ratio [Текст] / P. R. David, N. T. Simon // Ieee geoscience and remote sensing letters. -2006 . - № 3. - C. 112-116.

12. IndexDataBase[Электронный pecypc] / глав. страница. - Электрон. дан. - M., 2020. Режим доступа: https://www.indexdatabase.de/db/si.php.

13. Roberto, R. C. Remote sensing of the chlorophyll-a based on OLI/Landsat- 8 and MSI/Sentinel-2A (Barra Bonita reservoir, Brazil) [Текст] / R. C. Roberto // An Acad Bras Cienc. 2018. - № 1. - C. 1987-1999.

14. Saleem, S. B. Built-up area extraction using Landsat 8 OLI imagery [Текст] / S. B. Saleem, N. T. Kumar // GIScience \& Remote Sensing. - 2014. - № 51. - C. 445-467.

15. Spectral indices with multispectral satellite data [Электронныйресурс] / глав. страница. - Электрон. дан. - М., 2020. - Режим доступа: https:/www.geo.univer-sity/pages/spectral-indiceswith-multispectral-satellite-data.

(C) В. А. Косолапов, Е. П. Хлебникова, 2021 